\section{teatro al aire libre}

PHILIPPE CANAC, arquitecto

$146-52$
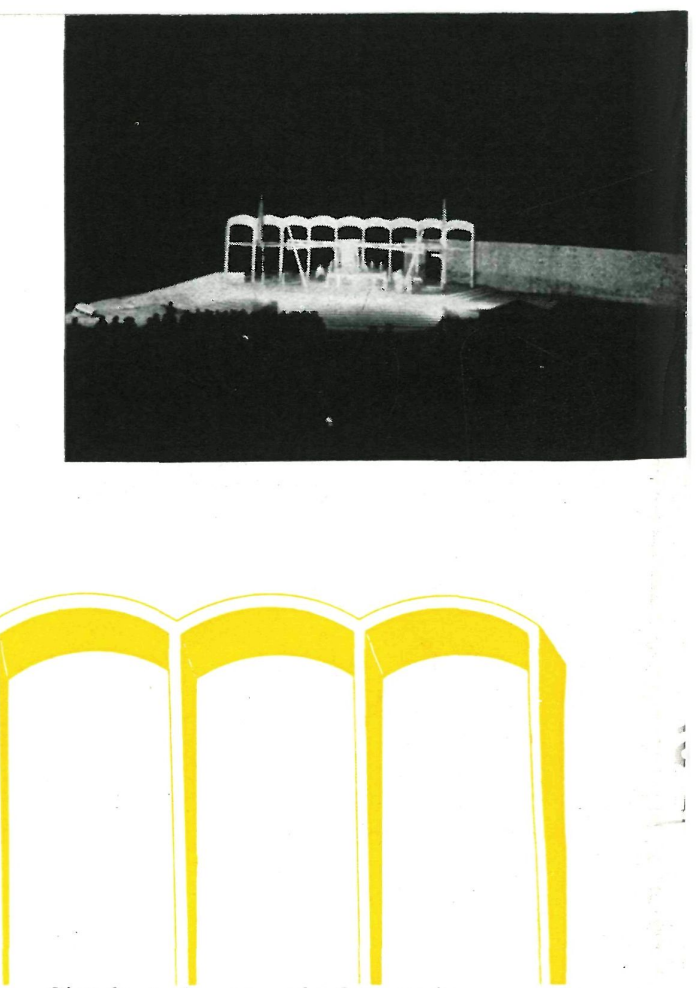

Siendo cada vez más frecuentes y numerosas las peregrinaciones a la basílica de Notre Dame, de Laus (Altos Alpes), su capacidad resultaba hace tiempo insuficiente para acoger a sus peregrinos. Este fué el motivo de crear,

en un terreno situado ante el atrio de la basílica,

un conjunto, que permitiese celebrar misas al aire libre, ceremonias litúrgicas o representaciones de teatro religioso y que dispusiese de todas las posibilidades para conseguir la libertad del juego escénico.

Este conjunto para celebraciones al aire libre, verdadero teatro, está formado por una plataforma elevada -la escena-,

ante la cual se distribuyen concéntricamente unas gradas que se elevan con pendiente del $12 \%$ hasta acomodar 4.000 personas distribuídas en abanico,

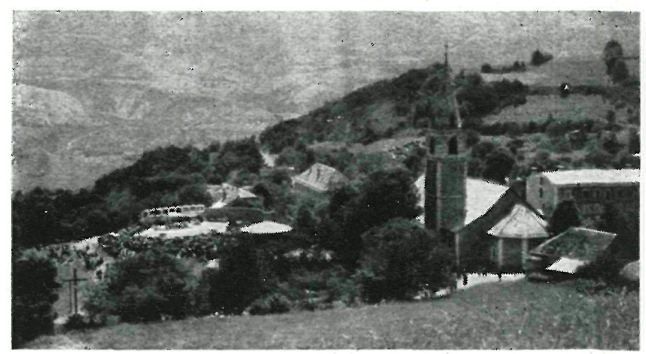

\section{hacia el frente común de la escena.}

La arquería, punto destacado del teatro, cierra y da importancia a la escena.

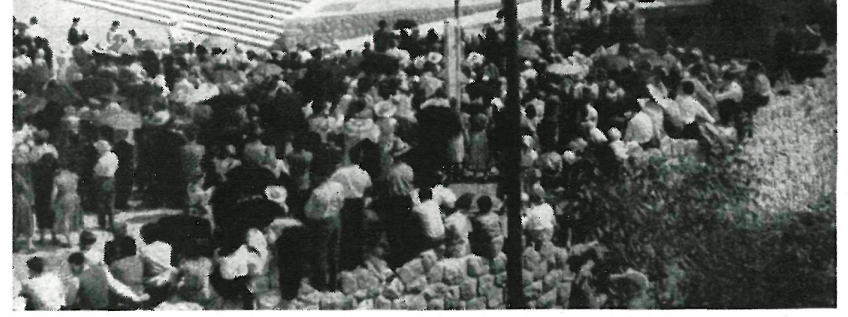




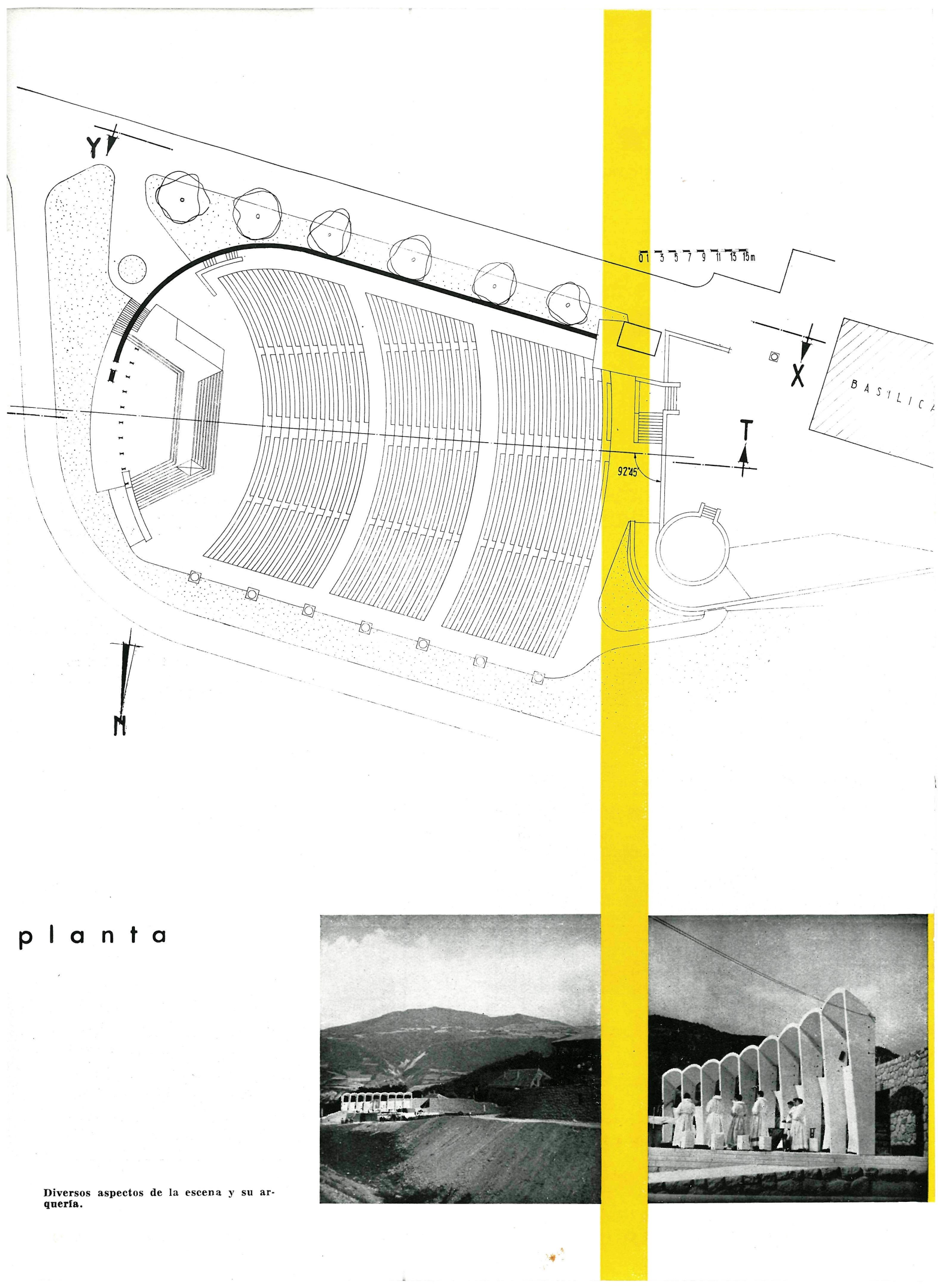




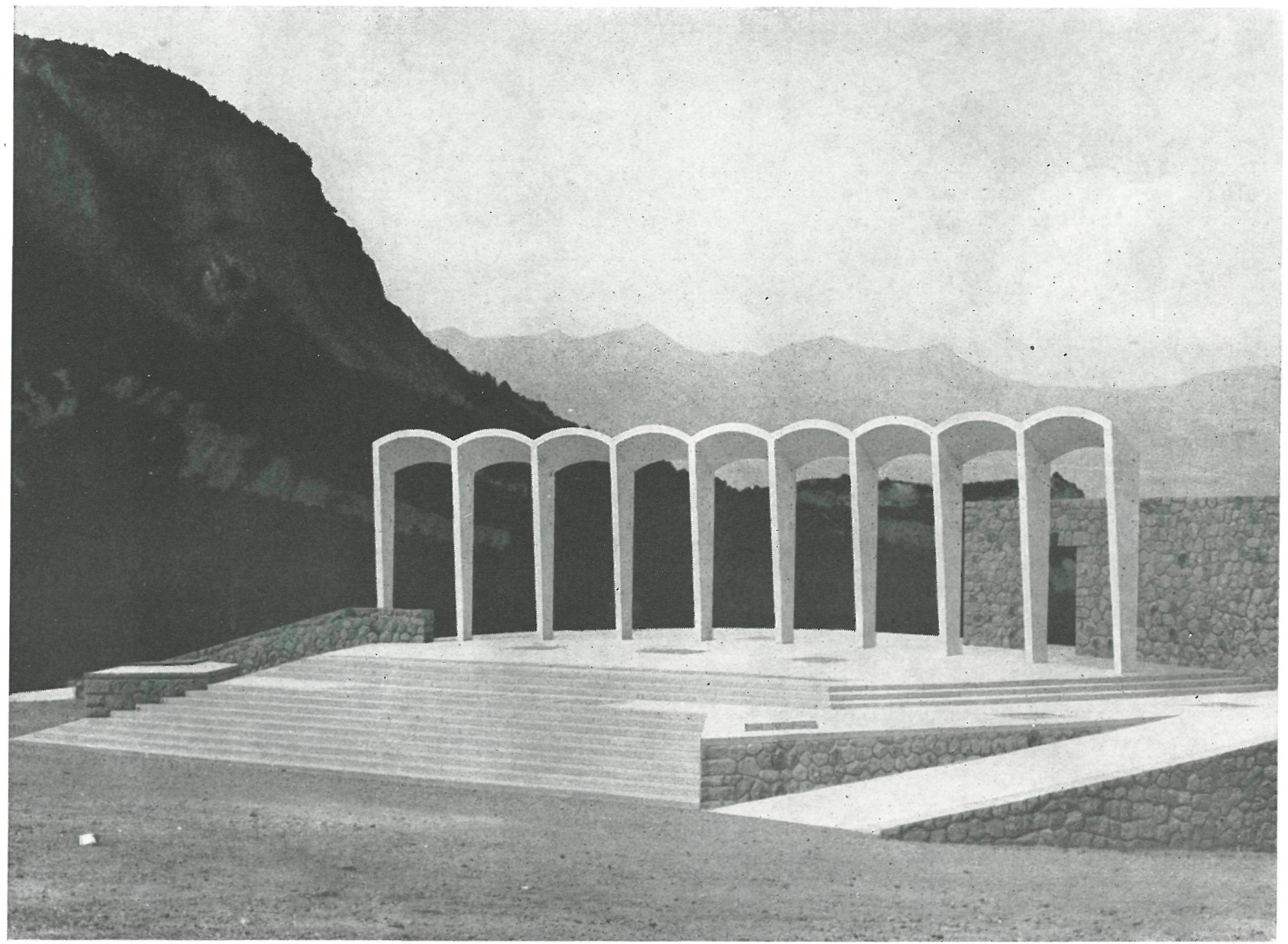

La plataforma del escenario es accesible por una serie de rampas y tramos en escalera, aprovechándose su interior para distribuir una capilla-sala de reunion, capaz para 400 personas. Presidiendo y cerrando la escena se ha construído una arquería de hormigón armado, tratado a cara vista y empleando cemento blanco. Los pies derechos y bóvedas conoidales de esta arquería han sido prefabricados en taller, consiguiéndose un perfecto acabado de sus aristas y paramentos.

Sobre la losa de hormigón armado, base de la escena, se han dispuesto una serie de agujeros y ranuras especiales para permitir una instalación cómoda de decorados y proyectores, al mismo tiempo de facilitar el acceso al escenario, de los actores, con absoluta libertad.
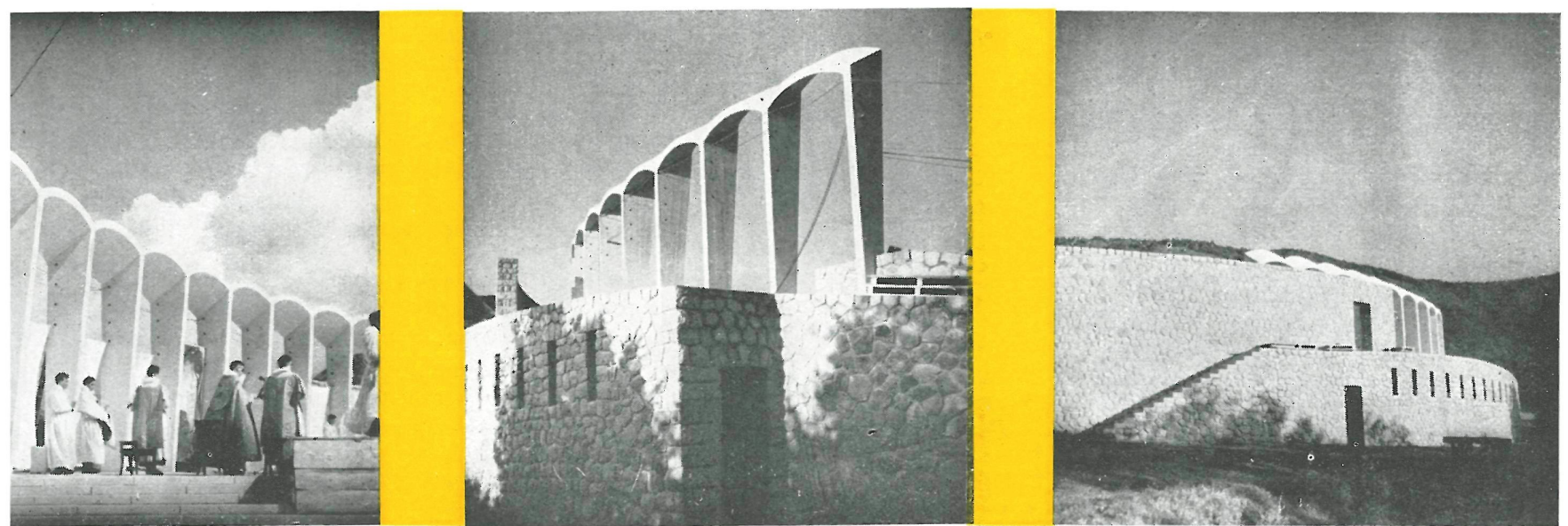


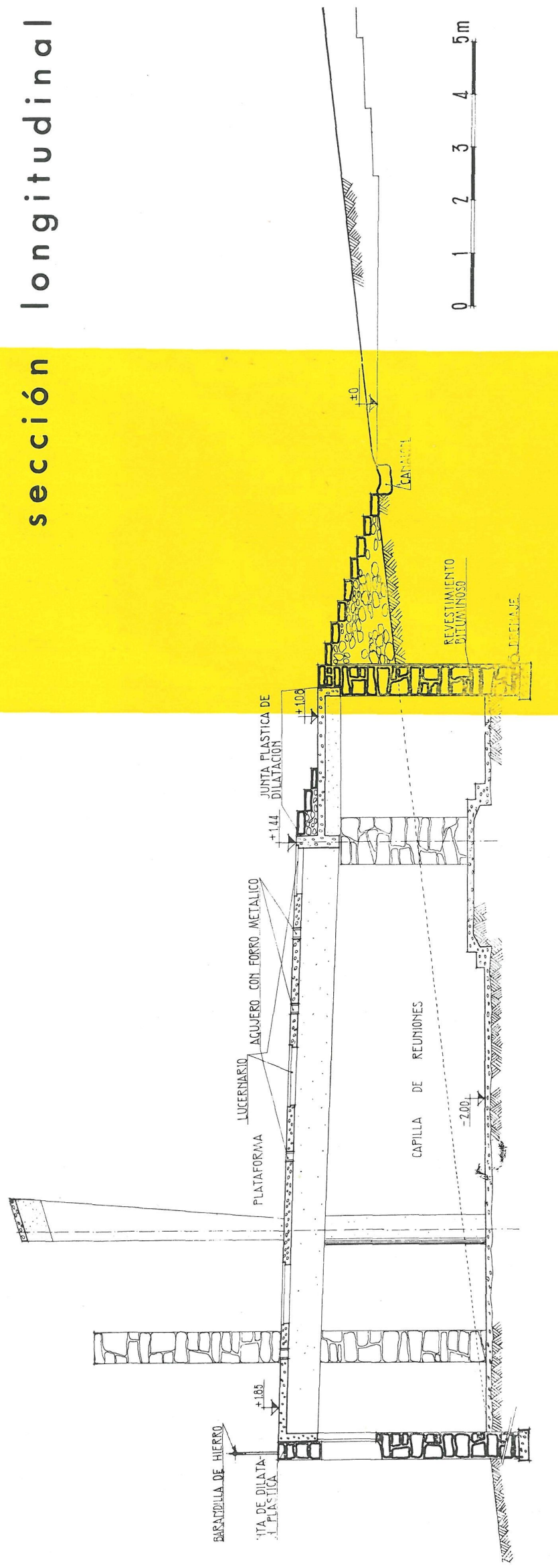

arquería de la escenc

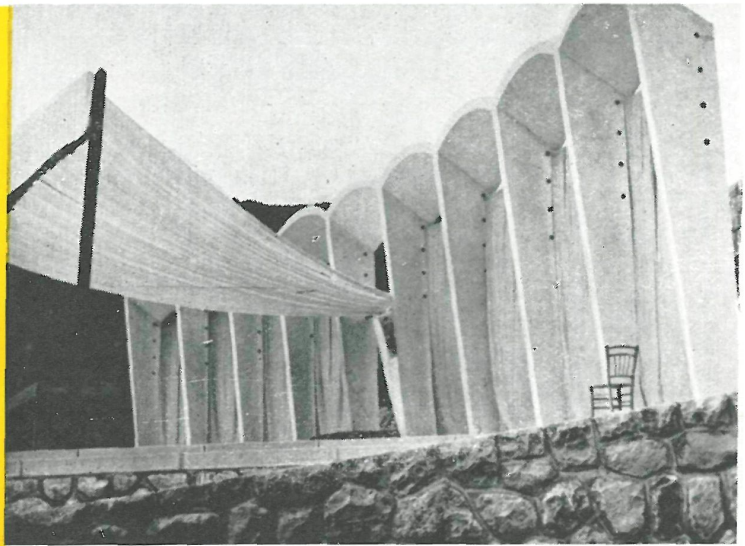

Estas aberturas están cerradas con dispositivos metálicos, y permiten al mismo tiempo jugar con la luz de la capilla inferior.

Un toldo de fácil montaje permite resguardar del sol la mayor parte de la escena.

Este toldo está formado por dos juegos de piezas triangulares idénticas,

uno blanco y otro de color variable, según la liturgia del día,

regulables a voluntad para disminuir la zona sombreada.

Un sistema de cables y tensores permiten variar la tensión y dirección de los mantos, cuyo tamaño ha procurado reducirse con objeto de disminuir la acción del viento sobre ellos.

Con esta disposición acertada y sencilla se ha logrado obtener un espacio gratamente ambientado, animado por el empleo de fábricas tradicionales de mampostería,

toldos de color y esbeltez y blancura de la arquería. Con todo ello se cumple perfectamente la misión encomendada:

amplitud de espacio y recurso ornamental. 